\title{
Bladder Organoids and Spheroids: Potential Tools for Normal and Diseased Tissue Modelling
}

\author{
IGOR VASYUTIN ${ }^{1 *}$, LILLIAN ZERIHUN $^{2 *}$, CRISTINA IVAN $^{3}$ and ANTHONY ATALA ${ }^{3}$ \\ ${ }^{1}$ Sechenov First Moscow State Medical University, Moscow, Russian Federation; \\ ${ }^{2}$ Columbia University College of Physicians and Surgeons, New York, NY, U.S.A.; \\ ${ }^{3}$ Wake Forest Institute for Regenerative Medicine, Winston-Salem, NC, U.S.A.
}

\begin{abstract}
Bladder-related diseases are among the most common and costly to the healthcare system, and therefore require new approaches to treatment. Organoids and spheroids are $3 D$ cultures that mimic organ features ex vivo and offer novel approaches for diagnostic and therapeutic assessment. The aim of this article was to provide a systematic review of the literature related to bladder organoids and spheroids, applied to disease diagnosis, characterization, and treatment. PubMed and Web of Science were utilized in March 2018 to compile 191 articles satisfying search criteria related to bladder organoids or spheroids and 58 articles were included in the final review. Finally, cell types and techniques utilized for spheroid and organoid manufacture were characterized. The applications of bladder carcinoma spheroids and organoids followed three themes: cancer characterization, diagnosis, and treatment. Tumor characterization studies included a focus on extracellular matrix, microenvironment, genetics, and growth of tumor cells. Diagnostic studies explored the use of endogenous fluorophores and white light for photodiagnosis. Treatment studies investigated cancer chemotherapy, immunotherapy, oncolytic viruses, and gene therapy. Ten studies explored hypericin as a tool for diagnostics and photodynamic therapy. Additionally, two studies applied organoids to urinary tract infections.
\end{abstract}

This article is freely accessible online.

*These Authors contributed equally to this study.

Correspondence to: Igor Vasyutin, Sechenov First Moscow State Medical University, 8 Trubetskaya st., Moscow, Russia. 119992. Tel: +7 9055193551, e-mail: ivasyutin@yahoo.com

Key Words: Bladder, in vitro model, organoids, spheroids, review.
Bladder-related diseases comprise a significant burden for world healthcare. Bladder cancer is the sixth most frequently diagnosed cancer in the United States (1) and has the highest lifetime treatment cost per patient of all cancer types, owing to a high post-treatment recurrence of $31-78 \%$ (2). Other common bladder-morbidities include urinary tract infections (UTIs) (3). In fact, the majority of women will develop UTIs in their lifetime, and the recurrence rate is one in four due to the tendency for bacteria to remain in the urinary tract after treatment (4). UTIs can pose major risks to the patient, including the potential for irreversible renal damage from kidney infection, birth complications in pregnant women, and life-threatening sepsis. Other conditions include congenital defects, inflammatory conditions and traumatic injuries.

Given the pressing burden of bladder-related morbidities, there is a need for new methods of characterization, diagnosis, and treatment. Current strategies for disease characterization and therapy development rely heavily on 2D cell-culture techniques with subsequent employment of animal models, which contribute to high research costs. However, 2D cell culture models are insufficient for capturing the complexity of in vivo architecture, such as extracellular matrix and cell-cell interactions that occur in 3D space (5). On the other hand, animal models often fail to recapitulate pathologies and treatment responses that occur in humans.

Regenerative medicine provides novel mechanisms for characterizing pathologies and developing treatments for diseases of the bladder. One promising area involves the use of organoids and spheroids, which are microscopic 3Dcultured cellular aggregates that mimic in vivo cellular processes (6). The benefits of 3D culture systems include a greater potential to capture in vivo microarchitecture, a more precise range of secretomes, and a closer mimicry of cellcell interactions as they occur inside the body (5).

This article aimed to systematically review the development of organoid and spheroid techniques for bladder research. The focus of this review is on organoids and 
spheroids derived from human bladder cells, including urothelial cells, bladder smooth-muscle cells, fibroblasts, and bladder carcinoma cells. In this review, we define organoids as in vitro culture systems replicating features of both benign and malignant bladder tissue organization, and spheroids as round-shaped cell aggregates maintained in culture. We excluded from our review those articles that focused on histoculture, i.e. small bladder tumor fragments that were maintained in cultural flasks for a short period.

\section{Materials and Methods}

The electronic databases PubMed and Web of Science were searched using the following terms: PubMed: (bladder OR urothelium OR urothel*) AND [(organoid OR organoids) OR (spheroid OR spheroids)] OR [(3D OR 3d OR 3 D OR 3 d OR three-dimensional OR three dimensional) AND culture)] + from 2000/01/01 (date 03.30.2018); Web of Science: bladder AND (organoid OR spheroid) + from 2000/01/01 (date 03.30.2018).

A total of 191 articles were returned for inclusion after removal of duplicates; 40 articles were excluded after screening of search results. After screening, 151 were read by the Authors and assessed for inclusion in our review using the following exclusion criteria: nonEnglish article, focus on non-human derived cells, non-bladder focused studies, non-utilization of organoids as specified in our working definition, non-original research/or review, and those for which full-text articles were not available. Ultimately, 58 articles were included in our study. Outline of the literature search in a Prisma Flow Diagram is presented in Figure 1 (7).

\section{Results}

We first surveyed the cell types and techniques that are typically used for the construction of bladder organoids and spheroids, including normal bladder cells and cancer cells of varying grades of differentiation. Next, we focused on the applications of organoids and spheroids to tumor targeting, characterization, diagnostics, cancer therapy, and infection.

\section{Cell Types}

Cell types employed in organoid and spheroid fabrication depended on the research purpose the model system was used for. Researchers used bladder carcinoma cells grade 1-4 for bladder cancer-related studies. Normal urothelial cells or fibroblasts were used in cancer-related studies as control cells or in order to recapitulate cancer cell interactions with benign tissues. Normal urothelial cells with or without stromal cells were used to establish normal bladder organoids in order to investigate native urothelial properties or urothelial response to injury. Different cell types used in bladder organoid and spheroid fabrication are listed in Table I.

Sources of cells: Commercial cell lines versus patient biopsies. Most articles used cells acquired from commercially available immortalized cell lines. A small number of studies acquired cancer cells directly from patient biopsies. Burgués et al. used cold cup biopsies from 40 patients with grade 1 or 2 superficial bladder tumors for chemosensitivity tests (8). Similarly, Bentivegna et al. collected transurethral resection material from 49 patients graded as carcinoma in situ (9), while others used low-grade noninfiltrating (17), low-grade infiltrating (2), high-grade noninfiltrating (3) and high-grade infiltrating (21) transitional cell carcinomas (9). Yoshida et al. used 176 specimens acquired from patients with Ta, T1, T2+, non-muscle invasive bladder cancer (NMIBC) or muscle-invasive bladder cancer (MIBC), low- or high-grade, flat or papillary tumors $(1,10,11)$.

Human urothelial cells. A majority of studies of normal bladder cells utilized normal human urothelium cells (12-21). Because the urothelium is the predominant site for bladder cancer, using normal human urothelial cells in experimental models is particularly important for cancer development and tumor targeting studies.

Human fibroblasts. Fibroblasts have been found to play a role in cancer progression, growth, and metastasis, as well as extracellular matrix production in both normal and cancerous cells (22). Thus, fibroblasts are important cell types for use in studies related to cancer characterization, proliferation, diagnosis, and therapeutics.

\section{Cancer cell lines}

Grade 1 carcinomas: Low-grade (grade 1) carcinomas possess similar morphology to normal bladder cells, are well-differentiated, and proliferate more slowly. These are often, but not always, confined to the urothelium (23). Thirteen articles used RT4 cells as a model of low-grade (grade 1) transitional cell carcinoma.

Other grade 1 bladder cancer cell lines included MGHU3 (six articles), which were usually paired with RT112 for comparative analyses between grade 1 and grade 2 tumors (24-27). Most of these studies focused on cancer treatment, including either chemotherapeutics or reoviral therapy. In addition, SW780 was a grade 1 cancer cell line used in three articles.

Grade 2 carcinomas: Moderately differentiated, or grade 2 carcinomas, are typically more aggressive and possess a greater risk of muscle invasion than grade 1 carcinomas (23).

Over one third of our articles (15 articles) utilized RT-112 as a model of moderately differentiated (grade 2) transitional cell carcinoma. Eight studies used this cell line for tumor diagnosis using hypericin and related analogs (15, 16, 19, 28-32); five studies utilized this cell line for cancer therapeutics, including chemotherapeutics and reoviral therapy (24-27, 33); and two studies used RT-112 for tumor characterization studies, including $\mathrm{pH}$ imbalance and tissue remodeling $(12,34)$. Other grade 2 carcinoma cell lines included the urothelial carcinoma cell line 5637 (5 articles). 


\section{PRISMA 2009 Flow Diagram}
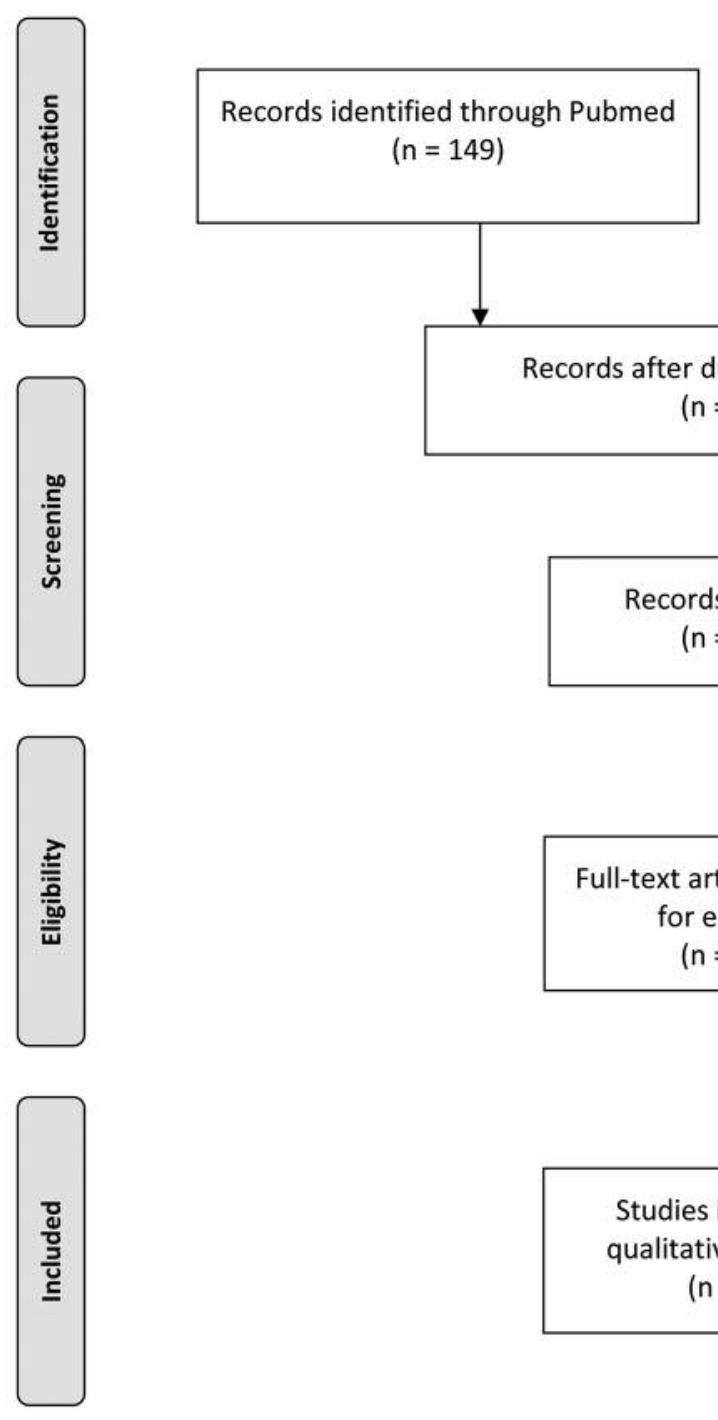

Records after duplicates removed

$$
\text { ( } n=191)
$$
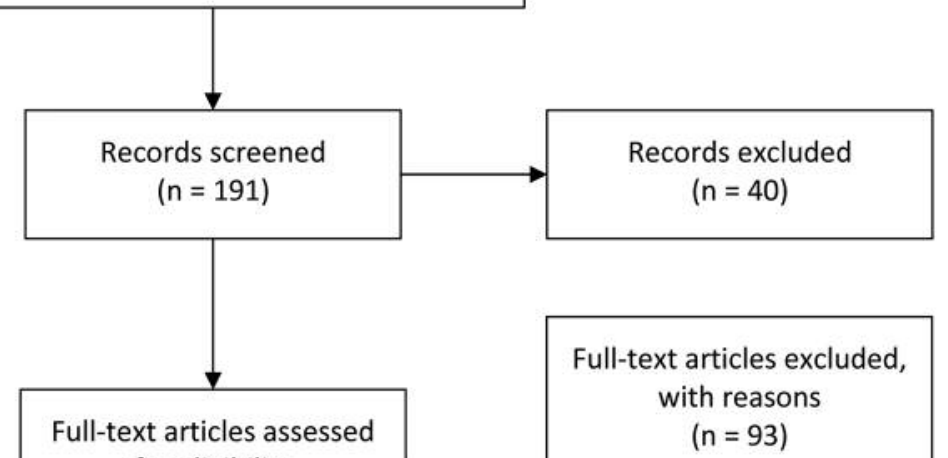

for eligibility

$(n=151)$

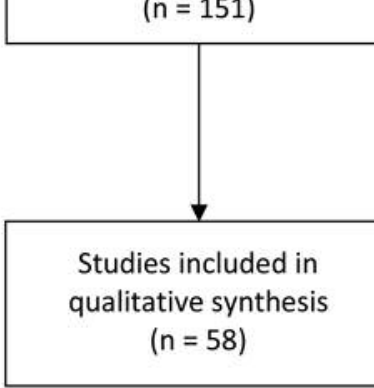

Nonhuman studies

$(n=13)$

Non-Bladder Studies

( $n=19$ )

Non-organoid focused

( $n=51)$

Review articles

$(n=6)$

Non-English

$(n=2)$

No Full Text

$(\mathrm{n}=2)$

Figure 1. Search strategy and selection of the studies for the review ( $n=58)$. The database search was performed to the PRISMA statement. For more details on the search strategy please see the Materials and Methods section.

Grade 3 carcinomas: High-grade tumors are abnormal and distinguishable from normal cells; they are more aggressive, exhibit a high proliferative rate, and recur or progress to muscle invasion and metastasize at a greater frequency (35).
Sixteen studies utilized T24 as a model of poorly differentiated (G3) transitional cell carcinoma (16-20, 26, 27, 36-42). J82 provided another popular model of grade 3 bladder cancer, with 9 studies included $(14,17,19,30,37$, 
Table I. Cell types in bladder organoids and spheroids.

\begin{tabular}{|c|c|}
\hline Cell type & Cell line (Ref) \\
\hline \multirow[t]{4}{*}{ Normal human urothelium } & Normal human urothelium cells unspecified (12-21) \\
\hline & SV40 immortalized human urothelium cell line (UROtsa) $(43,46,51)$ \\
\hline & SV40 immortalized human urothelium cell line (SV-HUC-1) $(1,37)$ \\
\hline & Normal human urothelium cell line ( $\alpha-E 7)(37)$ \\
\hline \multirow[t]{5}{*}{ Fibroblasts } & Human fibroblasts unspecified $(20,24)$ \\
\hline & Human fibroblasts (F2P6) (27) \\
\hline & Human dermal fibroblasts (HDF-n) (65) \\
\hline & Normal fibroblasts (CRL01129) (25) \\
\hline & Neonatal foreskin fibroblasts $(54)$ \\
\hline \multicolumn{2}{|l|}{ Bladder carcinoma } \\
\hline \multirow[t]{3}{*}{ Grade 1} & RT-4 $(11,12,14,17,20,27,30,46,56,57,59,64,69)$ \\
\hline & MGHU3 $(24-27,42,55)$ \\
\hline & $\operatorname{SW780}(14,47,65)$ \\
\hline \multirow[t]{2}{*}{ Grade 2} & RT-112 $(12,15-17,24-34)$ \\
\hline & $5637(11,27,37,53,59)$ \\
\hline \multirow[t]{3}{*}{ Grade 3} & T24 poorly differentiated $(16-20,26,27,36-42,70,71)$ \\
\hline & J82 muscle invasive $(14,17,19,30,37,43-46)$ \\
\hline & $\operatorname{HT} 1376(61,17,51,38,47)$ \\
\hline \multirow[t]{3}{*}{ Grade 4} & $253 \mathrm{JP}(14,26,27,45,47)$ \\
\hline & EJ138 cell lines poorly differentiated $(12,50)$ \\
\hline & TCCSUP metastatic $(14,46)$ \\
\hline
\end{tabular}

43-46). HT1376 use (5 studies) mostly focused on bladder cancer chemotherapy $(14,26,27,45,47)$, and one study utilizing $\mathrm{Hu} 1703 \mathrm{He}$ also focused on chemotherapy (48).

Muscle-invasive and metastatic models: Muscle invasive models and grade 4 carcinomas were typically used in tumor characterization studies; 253 JP (four studies) focused on characteristics of hypoxia and cell viability, as well as chemotherapy testing $(14,26,27,49)$. One study used the $253 \mathrm{~J}-\mathrm{BV}$ cell line (49). EJ (two studies) was used for gene therapy and characterization $(12,50)$, while TCCSUP was mentioned in two articles describing tumor characterization studies $(14,46)$.

\section{Production Techniques}

Organoids. No unified techniques for bladder organoid production was found in the studies. Generally, the approaches varied by culture condition, inclusion of stromal component, and shape. The organoid descriptions by article are presented in Table II.

Three articles aimed to establish multilayer urothelium cultures using normal or malignant urothelial cells. Rossi et al. investigated normal human urothelial cell line UROtsa grown in serum-free conditions on plastic surface. Under serum-free conditions, after reaching the confluence in culture, UROtsa cells developed multicellular polarized organoid structures. Freeze-fracture analysis revealed the presence of tight and gap junctions on the surface of the cells (51). Unlike the Rossi et al. study, Daher et al.'s group coated a microporous membrane with laminin/fibronectin/collagen IV to investigate in vitro growth and senescence of normal urothelium (13). There was a time-dependent profile change of cytokeratin (CK) expression. CK17 (a marker of basal cells) was expressed during the first 15 days, while CK18, a marker of superficial urothelial cells, was expressed after day 20. Similar culture systems were used for establishing a malignant urothelium multilayer culture in two other studies $(45,52)$. Exposing culture of urothelial cells to sterilized human urine, Horsley et al. established normal urothelial organoids which precisely recapitulated spatial organization and features of native urothelium (21). Initially, progenitor urothelial cells were kept on Millicell transwells in nominal culture media. When the culture reached confluence, the medium in the apical chamber of the culture wells was replaced with filter-sterilized human urine. The cultures were maintained for 14 days with periodic media and urine change. At the end of the culture period, cells were viable and had developed 5-7 layers with tightly-packed spheroid compact basal cells, intermediate cells and enlarged umbrella-like apical cells. The CK expression profile in the established organoids was similar to that of the native urothelium: CK8 expression throughout strata and CK20 and uroplakin III were expressed on the apical surface of the culture. Further analysis with electron microscopy confirmed the presence of the key features of the native urothelium in the organoids, including microplicae on the surface of apical cells. Urine was a key factor for formation of these organoids as 
Table II. Types of bladder cell-based organoids.

\begin{tabular}{ll}
\hline Cell type & Organoid description \\
\hline $\begin{array}{l}\text { Normal urothelial } \\
\text { UROtsa cell line }\end{array}$ & $\begin{array}{l}\text { Multicellular polarized organoid structures. Freeze-fracture analysis } \\
\text { revealed presence of tight and gap junctions on the surface of the cells. }\end{array}$ \\
Primary normal urothelium cells & $\begin{array}{l}\text { 3-4 Layers of urothelium on a microporous membrane coated with } \\
\text { laminin/fibronectin/collagen IV. }\end{array}$ \\
HBEP and their spontaneously immortalized, & HBLAK cells developed 5-7 layered urothelial tissue with tightly-packed \\
non-transformed counterparts (HBLAK) & spheroid compact basal cells and enlarged umbrella-like apical cells. \\
& Cytokeratin expression profile in the established organoids was similar to \\
native urothelium - CK8 throughout strata of the in vitro culture, while & CK20 and uroplakin III were expressed by umbrella-like cells on the apical \\
& surface of the culture. SEM and TEM analyses confirmed presence of key \\
features of the native urothelium in the organoids including microplicae on \\
the surface of apical umbrella cells.
\end{tabular}

Reference

Bladder carcinoma

Bladder carcinoma cell line 5637

Bladder carcinoma cell line MGH-U1

Bladder carcinoma cell lines HT-1376, and J-82

Bladder carcinoma + bladder stroma

Bladder carcinoma cell lines RT4, RT112, and EJ

Bladder carcinoma cell line 5637

Bladder cancer cell line $\mathrm{Hu} 1703 \mathrm{He}$

Primary bladder carcinoma cells

Bladder cancer cell line HBL-2, fibroblast cell line HBL-13

Normal urothelium cells, fibroblasts, human umbilical vein endothelial cells, RT4 and T24 bladder carcinoma cell lines.
4-6 Layers of closely packed urothelial cells on the surface of 2-3 $\mathrm{mm}^{3}$ SIS fragments.

$200 \mu \mathrm{m}$-Thick multilayered culture of bladder carcinoma cells on a microporous membrane coated with collagen IV.

190-310 $\mu$ m-Thick multilayered culture of bladder carcinoma cells on

a microporous membrane coated with collagen IV.

Multilayered epithelium from bladder carcinoma cells organized on a de-epithelialized benign bladder stroma with invasion into stroma for RT112 and EJ cells. The whole organoids were maintained on a microporous membrane in an air-liquid interface.

Bladder carcinoma cells attached to the basement membrane of de-epithelialized porcine bladder tissue sections. There was stromal invasion of bladder carcinoma cells after 12 days of organoid incubation. 300-450 $\mu \mathrm{m}$ Fragments of de-epithelialized normal bladder tissue embedded in bladder cancer cell spheroids.

Round organoids with a diameter of $500 \mu \mathrm{m}$, composed of a bladder stromal core covered with malignant urothelium.

Round organoids of varied sizes comprised of fibroblasts covered with bladder cancer cells.

Bladder wall organoid composing of stratified urothelium and stromal layer containing capillary-like network. Bladder cancer cell spheroids were implanted onto urothelium layer of the organoid to obtain in vitro bladder carcinoma model.

HBEP: Human bladder epithelial progenitor cells; CK: cytokeratin; SEM: scanning electron microscopy; TEM: transmission electron microscopy; SIS: decellularized porcine small intestine submucosa.

culture of the cells in chambers with the medium in lower and upper compartments did not lead to stratification of the urothelial cell monolayer (18). Smith et al. developed a culture system in which a suspension of malignant urothelial cells was mixed with 2-3 $\mathrm{mm}^{3}$ decellularized fragments of small intestine submucosa in a slowly rotating vessel (37). The fragments were completely covered with 4-6 layers of urothelial cells after 10 days of culture. Urothelial cells in the organoids expressed higher levels of epithelial (E)-cadherin, tight junction protein zonula occludens-1, CK20, and uroplakin-Ia compared to those in 2D culture.
Several investigators established organoids comprised of bladder carcinoma cells and bladder stroma. Booth et al. seeded bladder carcinoma cells on de-epithelialized benign bladder stroma pieces and maintained the organoids in an air-liquid interface (12). After 4 weeks of culture, the carcinoma cells developed multilayered epithelium separated from stroma with a basement membrane. Palmer et al. applied a similar approach to create an in vitro model of bladder-invasive carcinoma using de-epithelialized porcine bladder sections seeded with human bladder carcinoma cells (53). Vatne et al. constructed small round-shaped bladder 
Table III. Techniques used for bladder cell-based spheroid fabrication.

\begin{tabular}{ll}
\hline Spheroid type & Spheroid fabrication technique (Ref) \\
\hline Single-cell type & Cell culture in stirred suspension $(50,55,56)$ \\
& Seeding cells into V-bottomed wells coated with poly $(2$-hydroxyethyl methacrylate) $(60,66)$ \\
& Semisolid overlay technique $(15-19,28-34,36,43,44,47,64,69,70)$ \\
& Non-adherent technique $(1,9-11,38,40,57,59,63,65,71)$ \\
& Hanging-drop $(20,39,41,57)$ \\
Co-culture spheroids & Semisolid overlay technique followed by merging of spheroids from different cell types $(24-26,69)$ \\
& Cell co-culture on NanoCulture plate with a micro-square pattern $(42)$ \\
\hline
\end{tabular}

cancer organoids by merging carcinoma cell spheroids with 300-450 $\mu \mathrm{m}$ de-epithelialized normal bladder fragments (48). Burgués et al. described an approach to obtain organoids from primary bladder tumors in which they placed fragmented tumor from biopsies comprised of stroma and malignant urothelium into culture flasks coated with agarose. After 48 hours of incubation, some fragments were completely covered with malignant urothelial cells (8). Ingram et al. used a bioreactor with a slowly rotating chamber (6 rpm), providing constant free-fall slow shearing, to create organoids comprised of fibroblasts covered with malignant urothelial cells (54).

Ringuette Goulet et al. established a bladder cancer model by putting bladder cancer spheroids onto bladder wall organoids (20). Firstly, they manufactured a 3D model of bladder wall by seeding urothelial cells onto a fibroblast-collagen sheet stack containing human umbilical vein endothelial cells (HUVECs). After 21 days of the organoid production, the basement membrane had formed in the interface of fibroblasts and urothelium, and superficial cells of the multilayered urothelium had developed tight-junctions. In addition, HUVECs organized in a capillary-like network in the stromal compartment, that was confirmed by staining for CD31. For bladder cancer modelling, bladder carcinoma cell spheroids were implanted onto the bladder wall model. After 21 days, RT4 spheroids grew compactly, while T24 cells migrated through the basement membrane and invaded the stroma.

Spheroids. The most abundant approach for producing bladder cell spheroids is a semiliquid culture technique in which cells were suspended at densities of between $25 \times 10^{3}$ and $1,000 \times 10^{3}$ cells $/ \mathrm{ml}$ and seeded on pre-coated agarose plates. Other techniques include cell cultures constantly stirred in suspension, seeding cells into V-bottomed wells coated with poly(2-hydroxyethyl methacrylate), non-adherent techniques, hanging drop, and cultivation of cells on a plate with a micro-square pattern (Table III).

Spheroid diameter is dependent on incubation time. Xiao et al. showed that spheroids developed via cultivation of MGHU3 cells in stirred suspension gradually grew to
$300 \mu \mathrm{m}$ in diameter after 8-10 days of culture, and achieved a maximum diameter of $600 \mu \mathrm{m}$ on day 25 (55). In the same study, it was shown that the spheroids exhibited hypoxia and necrosis in the core when their sizes exceeded $500 \mu \mathrm{m}$. These findings are consistent with results obtained in another study where spheroids of 400-600 $\mu \mathrm{m}$ in diameter had central necrotic regions (56). A semi-solid technique was used to establish spheroids from normal human urothelium cells (15-19). Roelants et al. showed that cells in normal human urothelial spheroids do not express CK20; thus, urothelial cells in these spheroids do not correspond to fully differentiated superficial umbrella cells (17).

A non-adherent technique was shown to be a feasible method to establish spheroids from primary malignant tumor urothelial cells (10). Interestingly, the spheroid formation success rate was shown to depend on tumor stage. Cells from non-invasive tumors established spheroids with a success rate of $76.2 \%$, whereas cells from invasive tumors showed only a $42.1 \%$ success rate (1). Four studies used co-culture of spheroids in an in vitro bladder cancer model; these were comprised of fibroblasts and bladder carcinoma cells (2427). They were fabricated via co-cultivation of spheroids made from the two cell types in semisolid culture. When cultivated together, fibroblast spheroids were completely embedded in the cancer cell spheroids.

Amaral et al. compared properties of spheroids generated from RT4 cell line using ultra-low attachment and hangingdrop methods (57). Briefly, spheroids generated using the hanging-drop technique were more sphere-shaped and were smaller in diameter than spheroids generated with ultra-low attachment technique at the same seeding density. Interestingly, for the ultra-low attachment technique, the diameter of spheroids was more variable at low seeding density, while for the hanging-drop technique, the opposite trend was observed. In the same study, spheroid properties were compared to those of conventional 2D culture. The proliferative rate of cells in spheroid culture was about 4-times less compared to that in 2D culture. Additionally, according to lactate consumption, the metabolic activity of cells in spheroid culture was reduced. Thus, spheroid culture 
better recapitulates native tissue compare to $2 \mathrm{D}$ culture in terms of cell activity.

Ringuette Goulet et al. compared properties of spheroids generated from urothelial carcinoma cell lines of different grades (20). It is known that change in cadherin expression from epithelial type to neural type is one of the processes occurring during epithelial-mesenchymal transition (58). As expected, the lower grade carcinoma cell line RT4 expressed E-cadherin in spheroids, while T24 grade 3 bladder carcinoma cell spheroids expressed neural $(\mathrm{N})$-cadherin instead. Invasiveness of cells in spheroids was assessed by putting them into collagen I gel. T24 cells showed much higher invasiveness compared to RT4 cells (20).

\section{Applications}

Tumor characterization. Booth et al. used normal and cancerous bladder wall organoids to characterize expression of tenascin-C, an extracellular matrix glycoprotein, and transforming growth factor- $\beta 1$ in the urothelium, basement membrane, subepithelial vessels, and lamina propria. These markers were associated with tissue remodeling and invasion, with low transforming growth factor- $\beta 1$ expression in higher-grade tumors and increasing tenascin- $\mathrm{C}$ expression at the site of stromal invasion (12). Yoshida et al. showed a notable role of $\Delta \mathrm{Np} 63 \alpha$ in cancer cell implantation, adhesion, motility, and invasiveness. Cells in spheroids from bladder carcinoma cell lines and primary bladder tumors adhered to the collagen-coated surface of culture flasks and started to form a monolayer culture. This process was accompanied by decrease of $\Delta \mathrm{Np} 63 \alpha$ expression and cadherin change from epithelial (E-cadherin) to mesenchymal type (N-cadherin). Sandquist et al. characterized processes occurring in normal urothelial cells after exposure to carcinogens arsenite $\left(\mathrm{As}^{+3}\right)$ and cadmium $\left(\mathrm{Cd}^{+2}\right)$. Transformed cells expressed higher levels of $\mathrm{N}$ cadherin than parental normal urothelial cells, indicating epithelial-mesenchymal transition. However, N-cadherin expression decreased when the transformed cells were cultured as spheroids (46). These results suggest spheroid cultures support the epithelial phenotype of bladder cancer cells. In another study, spheroid cultures from primary bladder tumors were used to investigate the role of the $\mathrm{WNT} / \beta$-catenin pathway in tumor growth. Within a specific dose range, the WNT/ $\beta$-catenin pathway activator, CHIR, induced cell proliferation in spheroids. The role of the $\beta$ catenin pathway in CHIR-mediated induction of spheroid growth was confirmed when the researchers observed the reverse effect after inhibition of $\beta$-catenin with siRNA or pharmaceutic (59).

Miyake et al. used a NanoCulture plate with a microsquare pattern to investigate mechanisms modulating the interaction of bladder tumor cells with tumor-associated macrophages (TAMs) and cancer associated fibroblasts (CAFs). Due to the nano-scale square pattern, cells do not attach strongly to the base and start migrating, contact and adhere to each other forming spheroids. Using this culture system, it was shown that CXC chemokine ligand type 1 (CXCL1) mediated adhesion and population of bladder tumor spheroids by TAMs/CAFs. The spheroids had a higher ratio of bladder cancer cells to TAMs/CAFs when they were later infected with lentiviruses harboring CXCL1 expression vectors compared to empty vectors. Moreover, the addition of CXCL1-neutralizing antibody to the culture almost entirely inhibited formation of spheroids containing bladder cancer cells and TAMs/CAFs (42). Gottfried et al. cultured bladder carcinoma spheroids with monocytes in medium containing dendritic cell differentiation factors interleukin-4 and granulocyte-macrophage colonystimulating factor. After 5 to 7 days of cultivation, the spheroids were infiltrated by CD45+ dendritic cells. It was shown that CD1 a expression by tumor-associated dendritic cells was down-regulated after co-cultivation with the spheroids compared to control dendritic cells (44). The results show that the tumor environment had an inhibitory effect on dendritic cell phenotype.

Tumor genetics. Dangles et al. measured the quantitative differences in gene expression between three bladder cancer tissues, one from an adenocarcinoma and two from transitional cell carcinomas taken from cystectomy specimens. They quantified expression of 28 genes known to be involved in malignant growth and compared the expression of the in vivo profile to either a 1D single-cell suspension, 2D monolayer, or 3D multicellular spheroids. While all in vitro models differed in gene expression from the tumor specimen, the 3D model most resembled the in vivo condition (60).

Tumor microenvironment (Hypoxia, Redox, $\mathrm{pH}$ ). $\mathrm{pH}$ and hypoxia at the site of bladder cancer offers another avenue for characterization and treatment. Swietach et al. showed a $\mathrm{pH}$ gradient in cancer spheroids (34). Shin et al. developed an in vitro metastasis model with 253J-BV bladder cancer, and found a relationship between increased hypoxia, enhanced tumor migration, and matrix metalloproteinase-1 (MMP1), a matrix protein promoting angiogenesis, invasion and metastasis in muscle-invasive disease. Treatment of hypoxic spheroids with both an antioxidant (Nacetylcysteine) and an MMP inhibitor significantly reduced metastatic spread (49), indicating that redox regulation of MMP could provide an important pathway for promoting bladder cancer metastasis.

Cancer stem cells. Several studies used spheroid culture to propagate bladder cancer stem cells. It was previously 
shown that cancer stem cells, which are assumed to initiate tumor growth and are responsible for metastasis formation, form spheres in in vitro culture (61). Thus, researchers used spheroids to propagate and investigate cancer stem cells in vitro. Bentivegna et al. isolated bladder cancer cells from patient samples using culture conditions allowing spheroid formation and characterized the cells from spheroids for stem cell markers: CD133, POU class 5 homeobox 1 (Oct$3 / 4$ ) and nestin. They showed positive staining for the stem cell markers (9). Peek et al. successfully produced spheroids from bladder carcinoma cells and showed that cells in spheroids expressed higher levels of stem cell markers CD44 and CD49 (47). Wu et al. investigated the effects of the anticancer chemical silibinin, which disrupts the WNT/ $\beta$-catenin pathway. Treatment of bladder carcinoma cells with silibinin reduced expression of mesenchymal and stem cell markers and inhibited spheroid formation in dose-dependent manner. Further analysis confirmed that the effect was directly connected with the disruption of Wnt/ $\beta$-catenin pathway. Specifically, silibinin suppressed expression of zinc finger E-box binding homeobox 1 (ZEB1) gene, which is downstream of $\beta$ catenin (62).

Tumor targeting. Sixteen articles focused on radiolabeling and photodiagnosis as a novel non-invasive mechanism for diagnosing bladder cancer, using markers that selectively permeate tumors and emit detectable radioactive or fluorescent signals.

Endogenous fluorophores: Endogenous fluorophores are fluorescent molecules that already exist in cancer cells and can potentially be used in diagnostics. Two such fluorophores (NADH and flavins) were shown to have a potential for diagnostics of bladder carcinoma invasion. The researchers used organoids to study the invasion of cancer cells to muscle layer. They measured ratios of fluorescence for structural protein elastin against fluorescence of NADH and flavins and showed progression decrease of the ratio during the invasion process (53). These fluorophores allowed for monitoring of adherence, epithelialization, invasion of tissue, destruction of elastin, and other features of normal bladder extracellular matrices.

Hypericin diagnostics: The most widely studied photodiagnostic marker for bladder cancer using organoids was hypericin. Ten out of the 58 articles in our review described the application of spheroids and organoids to the use of hypericin or related fluorescent analogs.

Huygens et al. observed greater hypericin uptake and lower E-cadherin expression in three transitional cell carcinoma cell lines (J82, RT-4, and RT-112), but limited uptake and high E-cadherin expression in normal human urothelial cells, indicating an inverse relationship between E-cadherin expression and hypericin permeation (30).
Vandepitte et al. used a polyvinyl-L-pyrrolidone complex that de-aggregates hypericin and makes it water soluble and showed its higher accumulation in T24 spheroids compared to unmodified hypericin (18). Roelants et al. explored the differential uptake of hypericin in the presence and absence of human serum albumin (16), including a fluorescein isothiocyanate-labelled variety, which allowed for deeper penetration of hypericin into multicellular cancer spheroids $(17,19)$. Crnolatac et al. used lipophilic hypericin acid amide derivatives (AM6, AM8, AM12) associated with either low-density lipoproteins, high-density lipoproteins, or fetal bovine serum supplementation, and explored the impact of increased lipophilicity on binding to serum proteins in 2D and 3D cancer cell cultures (32).

Other photosensitizers: Three other articles described the use of photosensitizers that are distinct from the methods described above: iodine and Evans Blue. Roelants et al. showed that Evans Blue, a diazo dye used in white-light diagnosis, accumulated highly in J82 and T24 carcinoma spheroids but very minimally in normal human urothelial spheroids (19). Sjostrom et al. tested the accumulation of multiple iodine derivatives $\left({ }^{125} \mathrm{I}\right.$-labelled epidermal growth factor-dextran conjugate ( ${ }^{125}$ I-EGF-dextran $),{ }^{125} \mathrm{I}$-EGF, or ${ }^{125} \mathrm{I}$ ) in human bladder cancer spheroids and showed higher accumulation and cytotoxicity for ${ }^{125}$ I-EGF-dextran conjugates compare to ${ }^{125} \mathrm{I}$-EGF (56). Xiao et al. compared eight different photosensitizers on MGHU3 bladder cancer spheroids to determine the best photosensitizer for use in phototherapy (55). They reported hypocrellins and benzoporphyrin derivative monoacid ring $\mathrm{A}$ to be better than Photofrin, aluminum phthalocyanine chloride and protoporphyrin-IX for bladder cancer phototherapy due to their deeper penetration into the tumor tissue.

Tumor treatment. Chemotherapy: Burgués et al. used primary tumor-derived organoids to study chemotherapeutic sensitivity. The organoids were exposed to: epirubicin; epirubicin plus verapamil; doxorubicin; thiotepa; mitomycin $\mathrm{C}$; epirubicin plus ciprofloxacin; and ciprofloxacin. The results showed that the combination of epirubicin with ciprofloxacin was as effective as epirubicin alone, while the combination of epirubicin with verapamil significantly increased drug sensitivity compare to epirubicin alone. Mitomycin $\mathrm{C}$ was the best single agent (mean sensitivity: $50 \%$ ) followed by thiotepa (37\%), doxorubicin (7\%), and epirubicin (3\%) (8). Yoshida et al. specifically mapped intracellular changes in primary bladder carcinoma spheroids after mitomycin $\mathrm{C}$ treatment. Tumor cells stayed viable 2 hours after mitomycin $\mathrm{C}$ exposure, however, all cells had died 48 hours after mitomycin $\mathrm{C}$ treatment, showing decreased ATP levels and fragmented mitochondria. Despite cell death being accompanied by the expression of apoptotic factor caspase, cells were not rescued with caspase inhibitor Z-VADFMK, suggesting mitomycin-induced death was independent of 
caspase-activated apoptosis (11). Gabig et al. used similar spheroids for cytotoxicity testing of potential anticancer chemical Clostridium perfringens enterotoxin, and showed cell viability significantly decreased with time of treatment (63). Amaral et al. exposed bladder cancer spheroids to different concentrations of doxorubicin for 72 hours in culture to assess the half-maximal inhibitory concentration $\left(\mathrm{IC}_{50}\right)$ and compared the results with those of $2 \mathrm{D}$ cultures. They reported higher $\mathrm{IC}_{50}$ for spheroids than for $2 \mathrm{D}$ cultures, suggesting several possible factors describing the phenomenon, including low penetration of drug to deeper layers of cells in the spheroids, reduced drug uptake due to low $\mathrm{pH}$ at the spheroid center, and difference in proliferative stage of cells in 2D and 3D cultures (57). Decreased penetration of anticancer drugs in 3D environment was the scope of some other studies. Speers et al. used mitomycin C-resistant cancer spheroids for toxicity assessment against epirubicin; a sharp gradient of epirubicin uptake in spheroids was observed with confocal microscopy after exposure to $20 \mu \mathrm{g} / \mathrm{ml}$ for 1 hour (33). Tannock et al. revealed lower penetration of cancer drugs using a multilayered cancer cell culture on Teflon membranes, compared with penetration through the Teflon membrane alone (52).

For a tumor-invasive model where bladder cancer spheroids were seeded onto a urothelial layer of bladder wall organoids, Ringuette Goulet et al. used mitomycin C to inhibit carcinoma cell invasion (20). Mitomycin $\mathrm{C}$ at dose of $1 \mathrm{mg} / \mathrm{ml}$ reduced cancer cells invasion: there were only $34.4 \pm 1.8 \%$ invasive cells in the stromal compartment compared to $42.7 \pm 1.8 \%$ for the negative control phosphatebuffered saline. Kausch et al. observed RT- 4 cancer spheroid disaggregation after 12 days of treatment with $120 \mu \mathrm{M}$ of antisense oligodeoxyribonucleotide targeted against Ki-67 mRNA (64). Xiao measured the cytotoxic effect by incubating cancer-spheroids with bovine $\alpha$-lactalbumin and oleic acid for 4 hours and reported a dose-dependent bLACinducing apoptotic-like cell death (27). For paclitaxel, Vatne et al. found cancer cell viability was maintained after 4 weeks of incubation, but the ability to infiltrate benign bladder fragments was inhibited (48). Al-Abd et al., using a multilayered culture system, similarly found no effect of paclitaxel treatment on viability in HT1376 cancer cells, but saw reduced viability after paclitaxel exposure for the J-82 cell line (45). Braig et al. treated spheroids from T24 cell line with anticancer drug pretubulysin with and without tumor necrosis factor-related apoptosis-inducing ligand (TRAIL). The combination of the two drugs led to significantly higher cell death compared to treatment with each of the drugs separately (39). The same group treated T24 spheroids with a potent glycogen synthase kinase 3 beta inhibitor 6-bromoindirubin-30-oxime for 3 days and found enhanced cytotoxicity (41). Inhibiting growth pathways offers another promising therapeutic role. Okuyama et al. found that heregulin promoted growth of primary cancer tissue-derived spheroids, but heregulin inhibitors (phosphatidylinositol-3 kinase and mammalian target of rapamycin) and tyrosine kinase inhibiting drugs (lapatinib and erlotinib) might offer therapeutic mechanisms (10).

Fibroblast-based spheroids are useful comparative tools in chemotherapeutic studies. Kilani et al. assessed the effects of $10^{-4} \mathrm{M}$ of gemcitabine for 1-21 days on co-cultured fibroblasts and malignant urothelial cell spheroids. The timedependent profile of tumor cell death was determined, while fibroblasts remained unaffected by the drug even after 21 days of exposure (24). Moibi et al. found that a combination of gemcitabine $(10 \mu \mathrm{M})$ and TRAIL $(100 \mathrm{ng} / \mathrm{ml})$ induced greater apoptosis of tumor cells than didthe single agents, while fibroblasts remained unaffected (26). Frandsen et al. utilizing electroporation therapy with $\mathrm{CaCl}_{2}$ or bleomycin, found reduced spheroid size and cell death in carcinoma cell spheroids, but not fibroblasts spheroids, with a greater effect of $\mathrm{CaCl}_{2}$ (65).

Hypericin treatment and its dependence on oxygenation: Kamuhabwa et al. investigated the anticancer effect of photodynamic therapy with hypericin. T24 spheroids were treated with hypericin followed by light exposure. Cell survival in spheroids was a function of dose and intensity of light exposure, but generally was significantly higher than in monolayer culture. Fluorescent imaging showed that the spheroids had a negative hypericin gradient from the rim to the core (28). Hypoxic spheroid-core conditions were hypothesized to cause low hypericin sensitivity; this was investigated in two follow-up studies. Spheroid cultures were directly oxygenated or cultivated with perfluorodecalin before irradiation with light. Survival after photodynamic therapy was significantly lower for oxygenated and perflurodecalin-exposed spheroids than for non-oxygenated and non-exposed spheroids $(30,31)$.

Immunotherapy: Dangles et al. evaluated tumorinfiltrating lymphocyte (TIL) activation using spheroids in an in vitro tumor model. TIL activation was measured by analysis of the concentration of TIL-released cytokines in medium after co-culturing with spheroids or with a conventional 2D culture. The TILs infiltrated the spheroids after 6 hours of co-culture; however, the cytokine levels in spheroid/TIL co-culture were significantly lower than levels in $2 \mathrm{D}$ co-culture (66). The results suggest that the tumor architecture influences TIL activation and thus allows tumor cells to escape an immune response.

Oncolytic virus therapies: Kilani et al. used monocultured bladder cancer and co-cultured cancer-fibroblast spheroids treated with increasing doses of reovirus which infects cells via activated epidermal growth factor receptor (EGFR) pathway signaling for up to 14 days. Co-cultured spheroids were treated with increasing doses of reovirus for up to 14 days. Time-lapse and live/dead imaging revealed disaggregation and non-viability of bladder cancer spheroids, 
while fibroblast-based spheroids were not affected by the virus treatment (25). Van Beusechem et al. constructed adenoviruses expressing the targeting moiety that promotes virus entry via EGFR, and effects were studied in bladder cancer spheroids. Non-infected and infected cancer cells were aggregated in 99:1 or 9:1 ratios. WST-1 conversion assay for cell viability revealed that the 9:1 spheroids with modified-virus infected cells had two-fold lower cell viability compared to non-infected cells or non-modified virus-infected cells (36).

Gene therapy: One study aimed to establish the anticancer effect of gene therapy using spheroids as tumor models. Fullerton et al. investigated the toxicity of $\left({ }^{131} \mathrm{I}\right)$ metaiodobenzylguanidine $\left[\left({ }^{131} \mathrm{I}\right)-\mathrm{MIBG}\right]$ on cancer cells. Noradrenaline transporter (NAT) enables active uptake of $\left({ }^{131} \mathrm{I}\right)-\mathrm{MIBG}$; thus, cells expressing this promoter are mostly affected by $\left({ }^{131} \mathrm{I}\right)$-MIBG mediated radiotherapy. In this study, bladder cancer cells transfected with the gene for NAT were incubated with $\left({ }^{131} \mathrm{I}\right)-\mathrm{MIBG}$. Cells in spheroids transfected with the NAT gene demonstrated decreasing clonogenic capacity after incubation with $\left({ }^{131} \mathrm{I}\right)$-MIBG for 2 hours (50).

UTI: Two articles included in our review focused on infection. Smith et al. infected both monolayers and spheroids from 5637 cells with a strain of uropathogenic Escherichia coli, with or without a hemolysin gene mutation. They found that monolayers were heavily affected by the non-mutant $E$. coli strain. Organoids, however, retained some of the in vivo infection response mechanisms, attenuating the effect of infection for up to 3 hours. The hemolysin-mutant E. coli had little effect on monolayers or spheroids (37), indicating that hemolysin plays an important role in eliciting damage to urothelium.

Horsley et al. showed histopathological changes occurring in normal urothelium after UTI using organoids recapitulating mature urothelial architecture. After 2 hours of infection with Enterococcus faecalis, the apical cell layer of the urothelium organoids was shed, leaving basal and intermediate cells containing large intracellular bacterial colonies. Observation of intracellular colonies was confirmed after treatment of the organoids with $2,000 \mu \mathrm{g} / \mathrm{ml}$ of gentamicin for 2 hours - the gentamicin treatment made the supernatant above the organoid sterile, while the cell lysate was contaminated (21)

\section{Discussion}

Cell lines have been broadly used in cancer research as in vitro models for investigating anticancer therapy, providing insights into cancer biology and genetics. Particularly for bladder cancer, cell lines of all four bladder cancer grades have been established. Moreover, it was shown that primary bladder carcinoma cells of grades 1-3 can be obtained from tumor biopsy samples $(1,67)$. These primary cell cultures can provide specific per-patient information about tumor genetics and tumor sensitivity to different anticancer treatments. Cell cultures are usually maintained in vitro by cultivating them on plastic in $2 \mathrm{D}$. Although $2 \mathrm{D}$ cultures are broadly used and, in general, can be easily handled, as in vitro models, they are associated with multiple limitations and in many cases, 3D culture systems are preferred for research purposes.

\section{Genetic Drift in 2D Cell Cultures}

Each tumor has a unique mutational profile, while standard cell lines can cover only limited genetic alterations that occur in bladder cancer. Moreover, genomic and epigenomic variations were observed between cancer cell subpopulations within a single tumor. Thus, for personalized medicine, bladder cancer sensitivity to anticancer agents should be investigated in vitro with patient-derived bladder tumor cell cultures. Patient-derived bladder cancer cells maintained in 2D cultures can currently only be cultured for a limited period and may undergo additional clonal aberrations with passaging. In contrast, cells in 3D organoid cultures maintain their initial tumor genotype, can be kept for longer in culture, and survive freeze/thaw cycles.

\section{D Cultures Possess In Vivo-like Properties}

As can be shown from the systematic analysis provided in the article, 3D organoid systems possess in vivo-like properties which make them preferred models for deeper research of benign and malignant urothelial behavior. Firstly, organoid and spheroid cultures simulate three-dimensionality of natural urothelium and urothelial carcinomas. 3D cultures allow for better modelling of in vivo-like cell behaviors including cellcell interactions, $\mathrm{pH}$ gradients, extracellular matrix and different profile of bioactive molecules. Secondly, malignant urothelial multilayer organoids augmented with stromal components provide an opportunity to study bladder tumor invasiveness. In addition, spheroid cultures give the opportunity for cells of different origin to mix with each other and interact in a 3D environment. Using this property, researchers might be able to show specific mechanisms responsible for bladder cancer cells escaping the immune reaction.

\section{D Cultures Allow Expansion of Cancer Stem Cells}

Many studies showed that spheroids are needed to enrich cancer cell cultures with cancer stem cells from primary tumor samples as well as from some standard bladder cancer cell lines. These cancer stem cells are hypothesized to be responsible for tumor growth and, due to their low proliferative rate and high expression of drug efflux proteins, are resistant to most anticancer drugs. To affect these cells when developing 
anticancer treatment strategies, spheroid cultures that allow for in vitro cancer stem cell propagation are crucial.

\section{Organoid Cultures of Urothelium Provide Insights into UrotheliaI Development and Regeneration}

In particular, these organoids were used to describe the specific events occurring during UTI and bladder tumor invasion. As it was shown, a model of the urothelium can be fully developed in vitro with mature urothelial organization and cellular disposition without using a stromal component. Thus, basal urothelial progenitor cells are sufficient to establish the tissue. However, it was shown that while stromal cells are not crucial in urothelial regeneration, they can promote it via GIi1-mediated synthesis of WNT2, WNT4 and fibroblast growth factor 16 , which induce proliferation of sonic hedgehog-positive basal urothelial cells (68). Thus, in vitro studies of natural urothelial responses to uropathogenic infection and chemical injury may need an organoid system with a stromal component.

Development of organoids that more closely mimic the normal bladder architecture in vivo would allow for more complex studies to be performed. In addition, multi-organ systems composed of organoids seeded in microfluidic systems (organ-on-a-chip) can allow for greater complexity of experimental models of the human body. In the future, drug discovery may be simplified and made more costeffective through the use of organoids for candidate drug screening and toxicity testing.

\section{Conflicts of Interest}

The Authors declare no conflicts of interest in regard to this study.

\section{Authors' Contributions}

Igor Vasyutin, Lillian Zerihun and Cristina Ivan - defining search criteria. Igor Vasyutin and Lillian Zerihun - literature search, defining the articles to be included in the systematic review, writing. Cristina Ivan and Anthony Atala - review of the text.

\section{References}

1 Yoshida T, Okuyama H, Nakayama M, Endo H, Nonomura N, Nishimura K and Inoue M: High-dose chemotherapeutics of intravesical chemotherapy rapidly induce mitochondrial dysfunction in bladder cancer-derived spheroids. Cancer Sci 106: 69-77, 2015. PMID: 25363302, DOI: 10.1111/cas.12567.

2 Sylvester RJ, van der Meijden APM, Oosterlinck W, Witjes JA, Bouffioux C, Denis L, Newling DWW and Kurth K: Predicting recurrence and progression in individual patients with stage Ta T1 bladder cancer using EORTC risk tables: A combined analysis of 2596 patients from seven EORTC trials. Eur Urol 49: 466-465; discussion 475-477, 2006. PMID: 16442208, DOI: 10.1016/j.eururo.2005.12.031
3 Hooton TM, Bradley SF, Cardenas DD, Colgan R, Geerlings SE, Rice JC, Saint S, Schaeffer AJ, Tambayh PA, Tenke P, Nicolle LE and Infectious Diseases Society of America: Diagnosis, prevention, and treatment of catheter-associated urinary tract infection in adults: 2009 International Clinical Practice Guidelines from the Infectious Diseases Society of America. Clin Infect Dis Off Publ Infect Dis Soc Am 50: 625-663, 2010. PMID: 20175247.

4 Franco AVM: Recurrent urinary tract infections. Best Pract Res Clin Obstet Gynaecol 19: 861-873, 2005. PMID: 16298166, DOI: $10.1016 /$ j.bpobgyn.2005.08.003.

5 Edmondson R, Broglie JJ, Adcock AF and Yang L: Threedimensional cell culture systems and their applications in drug discovery and cell-based biosensors. Assay Drug Dev Technol 12: 207-218, 2014. PMID: 24831787, DOI: 10.1089/ adt.2014.573.

6 Fatehullah A, Tan SH and Barker N: Organoids as an in vitro model of human development and disease. Nat Cell Biol 18: 246-254, 2016. PMID: 26911908, DOI: 10.1038/ncb3312.

7 Moher D, Liberati A, Tetzlaff J, Altman DG and PRISMA Group: Preferred reporting items for systematic reviews and meta-analyses: The PRISMA statement. PLoS Med 6: e1000097, 2009. PMID: 19621072, DOI: 10.1371/journal.pmed.1000097.

8 Burgués JP, Gómez L, Pontones JL, Vera CD, Jiménez-Cruz JF and Ozonas M: A chemosensitivity test for superficial bladder cancer based on three-dimensional culture of tumour spheroids. Eur Urol 51: 962-969; discussion 969-970, 2007. PMID: 17084017, DOI: 10.1016/j.eururo.2006.10.034 .

9 Bentivegna A, Conconi D, Panzeri E, Sala E, Bovo G, Vigano P, Brunelli S, Bossi M, Tredici G, Strada G and Dalpra L: Biological heterogeneity of putative bladder cancer stem-like cell populations from human bladder transitional cell carcinoma samples. Cancer Sci 101: 416-424, 2010. PMID: 19961489, DOI: 10.1111/j.1349-7006.2009.01414.x.

10 Okuyama H, Yoshida T, Endo H, Nakayama M, Nonomura N, Nishimura $\mathrm{K}$ and Inoue $\mathrm{M}$ : Involvement of heregulin/HER3 in the primary culture of human urothelial cancer. J Urol 190: 302310, 2013. PMID: 23313199, DOI: 10.1016/j.juro.2012.12.106.

11 Yoshida T, Okuyama H, Nakayama M, Endo H, Tomita Y, Nonomura N, Nishimura K and Inoue M: Dynamic change in p63 protein expression during implantation of urothelial cancer clusters. Neoplasia 17: 574-585, 2015. PMID: 26297435, DOI: 10.1016/j.neo.2015.07.004.

12 Booth C, Harnden P, Selby PJ and Southgate J: Towards defining roles and relationships for tenascin-C and TGFbeta- 1 in the normal and neoplastic urinary bladder. J Pathol 198: 359-368, 2002. PMID: 12375269, DOI: 10.1002/path.1214.

13 Daher A, de Boer WI, Le Frere-Belda MA, Kheuang L, Abbou CC, Radvanyi F, Jaurand MC, Thiery JP, de Medina SGD and Chopin DK: Growth, differentiation and senescence of normal human urothelium in an organ-like culture. Eur Urol 45: 799-805, 2004. PMID: 15149756, DOI: 10.1016/j.eururo.2004.01.002.

14 Hurst RE, Kamat CD, Kyker KD, Green DE and Ihnat MA: A novel multidrug resistance phenotype of bladder tumor cells grown on Matrigel or SIS gel. Cancer Lett 217: 171-180, 2005. PMID: 15617834, DOI: 10.1016/j.canlet.2004.07.043.

15 Huygens A, Kamuhabwa AR, Van Laethem A, Roskams T, Van Cleynenbreugel B, Van Poppel H, Agostinis P and De Witte PAM: Enhancing the photodynamic effect of hypericin in tumour spheroids by fractionated light delivery in combination with hyperoxygenation. Int J Oncol 26: 1691-1697, 2005. PMID: 15870887, DOI: 10.3892/ijo.26.6.1691. 
16 Roelants M, Van Cleynenbreugel B, Lerut E, Van Poppel H and de Witte PAM: Human serum albumin as key mediator of the differential accumulation of hypericin in normal urothelial cell spheroids versus urothelial cell carcinoma spheroids. Photochem Photobiol Sci 10: 151-159, 2011. PMID: 21103512 DOI: 10.1039/c0pp00109k.

17 Roelants M, Van Cleynenbreugel B, Van Poppel H, Lerut E and de Witte PAM: Use of fluorescein isothiocyanate-human serum albumin for the intravesical photodiagnosis of non-muscleinvasive bladder cancer: An in vitro study using multicellular spheroids composed of normal human urothelial and urothelial cell carcinoma cell lines. BJU Int 108: 455-459, 2011. PMID: 21156021, DOI: 10.1111/j.1464-410X.2010.09951.x.

18 Vandepitte J, Roelants M, Van Cleynenbreugel B, Hettinger K, Lerut E, Van Poppel H and de Witte PAM: Biodistribution and photodynamic effects of polyvinylpyrrolidone-hypericin using multicellular spheroids composed of normal human urothelial and T24 transitional cell carcinoma cells. J Biomed Opt 16: 018001, 2011. PMID: 21280926, DOI: 10.1117/1.3533316.

19 Roelants M, Huygens A, Crnolatac I, Van Cleynenbreugel B, Lerut E, Van Poppel H and de Witte PAM: Evans blue as a selective dye marker for white-light diagnosis of non-muscleinvasive bladder cancer: An in vitro study. Bju Int 109: 300-305, 2012. PMID: 21854534, DOI: 10.1111/j.1464-410X.2011. 10465.x.

20 Ringuette Goulet C, Bernard G, Chabaud S, Couture A, Langlois A, Neveu B, Pouliot F and Bolduc S: Tissue-engineered human 3D model of bladder cancer for invasion study and drug discovery. Biomaterials 145: 233-241, 2017. PMID: 28888113, DOI: $10.1016 /$ j.biomaterials.2017.08.041.

21 Horsley H, Dharmasena D, Malone-Lee J and Rohn JL: A urinedependent human urothelial organoid offers a potential alternative to rodent models of infection. Sci Rep 8: 1238, 2018. PMID: 29352171, DOI: 10.1038/s41598-018-19690-7.

22 Kalluri R and Zeisberg M: Fibroblasts in cancer. Nat Rev Cancer 6: 392-401, 2006. PMID: 16572188, DOI: 10.1038/nrc1877.

23 Sanli O, Dobruch J, Knowles MA, Burger M, Alemozaffar M, Nielsen ME and Lotan Y: Bladder cancer. Nat Rev Dis Primer 3: 17022, 2017. PMID: 28406148, DOI: 10.1038/nrdp.2017.22.

24 Kilani RT, Tamimi Y, Karmali S, Mackey J, Hanel EG, Wong KK and Moore RB: Selective cytotoxicity of gemcitabine in bladder cancer cell lines. Anticancer Drugs 13: 557-566, 2002. PMID: 12172501.

25 Kilani RT, Tamimi Y, Hanel EG, Wong KK, Karmali S, Lee PWK and Moore RB: Selective reovirus killing of bladder cancer in a co-culture spheroid model. Virus Res 93: 1-12, 2003. PMID: 12727337, DOI: 10.1016/S0168-1702(03)00045-5.

26 Moibi JA, Mak AL, Sun B and Moore RB: Urothelial cancer cell response to combination therapy of gemcitabine and TRAIL. Int J Oncol 39: 61-71, 2011. PMID: 21537842, DOI: 10.3892/ ijo.2011.1023.

27 Xiao Z, Mak A, Koch K and Moore RB: A molecular complex of bovine milk protein and oleic acid selectively kills cancer cells in vitro and inhibits tumour growth in an orthotopic rat bladder tumour model. Bju Int 112: E201-E210, 2013. PMID: 23356235, DOI: 10.1111/j.1464-410X.2012.11737.x.

28 Kamuhabwa AAR, Huygens A and De Witte PAM: Photodynamic therapy of transitional cell carcinoma multicellular tumor spheroids with hypericin. Int J Oncol 23: 1445-1450, 2003. PMID: 14532989, DOI: 10.3892/ijo.23.5.1445.
29 Huygens A, Huyghe D, Bormans G, Verbruggen A, Kamuhabwa AR, Roskams $T$ and de Witte PAM: Accumulation and photocytotoxicity of hypericin and analogs in two- and threedimensional cultures of transitional cell carcinoma cells. Photochem Photobiol 78: 607-614, 2003. PMID: 14743871, DOI: 10.1562/0031-8655(2003)0780607AAPOHA2.0.CO2.

30 Huygens A, Kamuhabwa AR, Roskams T, Van Cleynenbreugel B, Van Poppel H and De Witte PAM: Permeation of hypericin in spheroids composed of different grade transitional cell carcinoma cell lines and normal human urothelial cells. J Urol 174: 69-72, 2005. PMID: 15947580, DOI: 10.1097/01.ju.0000162037.49102.56.

31 Kamuhabwa AR, Huygens A, Roskams T and De Witte PAM: Enhancing the photodynamic effect of hypericin in human bladder transitional cell carcinoma spheroids by the use of the oxygen carrier, perfluorodecalin. Int J Oncol 28: 775-780, 2006. PMID: 16465384, DOI: 10.3892/ijo.28.3.775.

32 Crnolatac I, Huygens A, Agostinis P, Kamuhabwa AR, Maes J, Van Aerschot A and De Witte PAM: In vitro accumulation and permeation of hypericin and lipophilic analogues in 2-D and 3D cellular systems. Int J Oncol 30: 319-324, 2007. PMID: 17203212, DOI: $10.3892 /$ ijo.30.2.319.

33 Speers AG, Lwaleed BA, Featherstone JM and Cooper AJ: Multidrug resistance in a urothelial cancer cell line after 3, 1hour exposures to mitomycin C. J Urol 178: 2171-2175, 2007. PMID: 17870115, DOI: 10.1016/j.juro.2007.06.047.

34 Swietach P, Wigfield S, Cobden P, Supuran CT, Harris AL and Vaughan-Jones RD: Tumor-associated carbonic anhydrase 9 spatially coordinates intracellular $\mathrm{pH}$ in three-dimensional multicellular growths. J Biol Chem 283: 20473-20483, 2008. PMID: 18482982, DOI: 10.1074/jbc.M801330200.

35 Kitamura $\mathrm{H}$ and Kakehi Y: Treatment and management of highgrade T1 bladder cancer: What should we do after second TUR? Jpn J Clin Oncol 45: 315-322, 2015. PMID: 25583419, DOI: $10.1093 /$ jjco/hyu 219 .

36 van Beusechem VW, Mastenbroek DCJ, van den Doel PB, Lamfers MLM, Grill J, Wurdinger T, Haisma HJ, Pinedo HM and Gerritsen WR: Conditionally replicative adenovirus expressing a targeting adapter molecule exhibits enhanced oncolytic potency on CAR-deficient tumors. Gene Ther 10: 1982-1991, 2003. PMID: 14528322, DOI: 10.1038/sj.gt.3302103.

37 Smith YC, Grande KK, Rasmussen SB and O'Brien AD: Novel three-dimensional organoid model for evaluation of the interaction of uropathogenic Escherichia coli with terminally differentiated human urothelial cells. Infect Immun 74: 750-757, 2006. PMID: 16369034, DOI: 10.1128/IAI.74.1.750-757.2006.

38 Zhu D, Wan X, Huang H, Chen X, Liang W, Zhao F, Lin T, Han $\mathrm{J}$ and Xie W: Knockdown of BMII inhibits the stemness properties and tumorigenicity of human bladder cancer stem cell-like side population cells. Oncol Rep 31: 727-736, 2014. PMID: 24337040, DOI: 10.3892/or.2013.2919.

39 Braig S, Wiedmann RM, Liebl J, Singer M, Kubisch R, Schreiner L, Abhari BA, Wagner E, Kazmaier U, Fulda S and Vollmar AM: Pretubulysin: A new option for the treatment of metastatic cancer. Cell Death Dis 5: e1001, 2014. PMID: 24434509, DOI: 10.1038/cddis.2013.510.

40 Ojha R, Jha V, Singh SK and Bhattacharyya S: Autophagy inhibition suppresses the tumorigenic potential of cancer stem cell enriched side population in bladder cancer. Biochim Biophys Acta 1842: 2073-2086, 2014. PMID: 25020236, DOI: 10.1016/j.bbadis.2014.07.007. 
41 Braig S, Bischoff F, Abhari BA, Meijer L, Fulda S, Skaltsounis $\mathrm{L}$ and Vollmar AM: The pleiotropic profile of the indirubin derivative 6BIO overcomes TRAIL resistance in cancer. Biochem Pharmacol 91: 157-167, 2014. PMID: 25069048, DOI: 10.1016/j.bcp.2014.07.009.

42 Miyake M, Hori S, Morizawa Y, Tatsumi Y, Nakai Y, Anai S, Torimoto K, Aoki K, Tanaka N, Shimada K, Konishi N, Toritsuka M, Kishimoto $\mathrm{T}$, Rosser $\mathrm{CJ}$ and Fujimoto $\mathrm{K}$ : CXCL1-mediated interaction of cancer cells with tumorassociated macrophages and cancer-associated fibroblasts promotes tumor progression in human bladder cancer. Neoplasia 18: 636-646, 2016. PMID: 27690238, DOI: 10.1016/j.neo.2016.08.002.

43 Lottner C, Knuechel R, Bernhardt $G$ and Brunner $H$ : Distribution and subcellular localization of a water-soluble hematoporphyrin-platinum(II) complex in human bladder cancer cells. Cancer Lett 215: 167-177, 2004. PMID: 15488635, DOI: 10.1016/j.canlet.2004.06.035.

44 Gottfried E, Kunz-Schughart LA, Ebner S, Mueller-Klieser W, Hoves S, Andreesen R, Mackensen A and Kreutz M: Tumorderived lactic acid modulates dendritic cell activation and antigen expression. Blood 107: 2013-2021, 2006. PMID: 16278308, DOI: 10.1182/blood-2005-05-1795.

45 Al-Abd AM, Lee J-H, Kim SY, Kun N and Kuh H-J: Novel application of multicellular layers culture for in situ evaluation of cytotoxicity and penetration of paclitaxel. Cancer Sci 99: 423431, 2008. PMID: 18271941, DOI: 10.1111/j.1349-7006.2007. 00700.x.

46 Sandquist EJ, Somji S, Dunlevy JR, Garrett SH, Zhou XD, Slusser-Nore A and Sens DA: Loss of N-cadherin expression in tumor transplants produced from $\mathrm{AS}^{+3}$ - and $\mathrm{CD}^{+2}$ - transformed human urothelial (UROtsa) Cell Lines. Plos One 11: e0156310, 2016. PMID: 27224422, DOI: 10.1371/journal.pone.0156310.

47 Peek EM, Li DR, Zhang H, Kim HP, Zhang B, Garraway IP and Chin AI: Stromal modulation of bladder cancer-initiating cells in a subcutaneous tumor model. Am J Cancer Res 2: 745-751, 2012. PMID: 23226620.

48 Vatne V, Litlekalsoey J, Wentzel-Larsen T and Hostmark J: The in vitro effect of paclitaxel on a LacZ-transfected malignant transitional cell line. Anticancer Res 25: 2097-2104, 2005. PMID: 16158950.

49 Shin DH, Dier U, Melendez JA and Hempel N: Regulation of MMP-1 expression in response to hypoxia is dependent on the intracellular redox status of metastatic bladder cancer cells Biochim Biophys Acta 1852: 2593-2602, 2015. PMID: 26343184, DOI: 10.1016/j.bbadis.2015.09.001.

50 Fullerton NE, Mairs RJ, Kirk D, Keith WN, Carruthers R, McCluskey AG, Brown M, Wilson L and Boyd M: Application of targeted radiotherapy/gene therapy to bladder cancer cell lines. Eur Urol 47: 250-256, 2005. PMID: 15661422, DOI: 10.1016/j.eururo.2004.09.009.

51 Rossi MR, Masters JR, Park S, Todd JH, Garrett SH, Sens MA, Somji S, Nath J and Sens DA: The immortalized UROtsa cell line as a potential cell culture model of human urothelium. Environ Health Perspect 109: 801-808, 2001. PMID: 11564615, DOI: $10.1289 /$ ehp.01109801.

52 Tannock IF, Lee CM, Tunggal JK, Cowan DSM and Egorin MJ: Limited penetration of anticancer drugs through tumor tissue: A potential cause of resistance of solid tumors to chemotherapy. Clin Cancer Res 8: 878-884, 2002. PMID: 11895922.
53 Palmer S, Litvinova K, Dunaev A, Fleming S, McGloin D and Nabi G: Changes in autofluorescence based organoid model of muscle-invasive urinary bladder cancer. Biomed Opt Express 7: 1193-1200, 2016. PMID: 27446646, DOI: 10.1364/BOE.7.001193.

54 Ingram M, Techy GB, Ward BR, Imam SA, Atkinson R, Ho H and Taylor CR: Tissue-engineered tumor models. Biotech Histochem 85: 213-229, 2010. PMID: 20482463, DOI: 10.3109/10520295.2010.483655.

55 Xiao ZW, Hansen CB, Allen TM, Miller GG and Moore RB: Distribution of photosensitizers in bladder cancer spheroids: Implications for intravesical instillation of photosensitizers for photodynamic therapy of bladder cancer. J Pharm Pharm Sci 8: 536-543, 2005. PMID: 16401399.

56 Sjostrom A, Bue P, Malmstrom PU and Carlsson J: Binding of I-125 after administration of I-125-EGF-dextran, I-125-EGF or I-125 to human bladder cancer spheroids. Int J Oncol 17: 559564, 2000. PMID: 10938398, DOI: 10.3892/ijo.17.3.559.

57 Amaral RLF, Miranda M, Marcato PD and Swiech K: Comparative analysis of 3D bladder tumor spheroids obtained by forced floating and hanging drop methods for drug screening. Front Physiol 8: 605, 2017. PMID: 28878686, DOI: 10.3389/ fphys.2017.00605.

58 Kalluri $\mathrm{R}$ and Weinberg RA: The basics of epithelialmesenchymal transition. J Clin Invest 119: 1420-1428, 2009. PMID: 19487818, DOI: 10.1172/JCI39104.

59 Yoshida T, Sopko NA, Kates M, Liu X, Joice G, McConkey DJ and Bivalacqua TJ: Three-dimensional organoid culture reveals involvement of $\mathrm{WNT} / \beta$-catenin pathway in proliferation of bladder cancer cells. Oncotarget 9: 11060-11070, 2018. PMID: 29541396, DOI: 10.18632 /oncotarget.24308.

60 Dangles V, Lazar V, Validire P, Richon S, Wertheimer M, Laville V, Janneau JL, Barrois M, Bovin C, Poynard T, Vallancien G and Bellet D: Gene expression profiles of bladder cancers: evidence for a striking effect of in vitro cell models on gene patterns. $\mathrm{Br}$ J Cancer 86: 1283-1289, 2002. PMID: 11953886, DOI: 10.1038/sj.bjc.6600239.

61 Jaggupilli A and Elkord E: Significance of CD44 and CD24 as cancer stem cell markers: an enduring ambiguity. Clin Dev Immunol 2012: 708036, 2012. PMID: 22693526, DOI: $10.1155 / 2012 / 708036$.

$62 \mathrm{Wu}$ K, Ning Z, Zeng J, Fan J, Zhou J, Zhang T, Zhang L, Chen Y, Gao Y, Wang B, Guo P, Li L, Wang X and He D: Silibinin inhibits $\beta$-catenin/ZEB1 signaling and suppresses bladder cancer metastasis via dual-blocking epithelial-mesenchymal transition and stemness. Cell Signal 25: 2625-2633, 2013. PMID: 24012496, DOI: 10.1016/j.cellsig.2013.08.028.

63 Gabig TG, Waltzer WC, Whyard T and Romanov V: Clostridium perfringens enterotoxin as a potential drug for intravesical treatment of bladder cancer. Biochem Biophys Res Commun 478: 887-892, 2016. PMID: 27520378, DOI: 10.1016/ j.bbrc.2016.08.046.

64 Kausch I, Lingnau A, Endl E, Sellmann K, Deinert I, Ratliff TL, Jocham D, Sczakiel G, Gerdes J and Bohle A: Antisense treatment against Ki-67 mRNA inhibits proliferation and tumor growth in vitro and in vivo. Int J Cancer 105: 710-716, 2003. PMID: 12740923, DOI: 10.1002/ijc.11111.

65 Frandsen SK, Gibot L, Madi M, Gehl J and Rols M-P: Calcium electroporation: Evidence for differential effects in normal and malignant cell lines, evaluated in a 3D spheroid model. PloS One 10: e0144028, 2015. PMID: 26633834, DOI: 10.1371/ journal.pone. 0144028 . 
66 Dangles V, Validire P, Wertheimer M, Richon S, Bovin C, Zeliszewski D, Vallancien G and Bellet D: Impact of human bladder cancer cell architecture on autologous T-lymphocyte activation. Int J Cancer 98: 51-56, 2002. PMID: 11857385, DOI: 10.1002/ijc.10140.

67 Seifert H-H, Meyer A, Cronauer MV, Hatina J, Müller M, Rieder H, Hoffmann MJ, Ackermann R and Schulz WA: A new and reliable culture system for superficial low-grade urothelial carcinoma of the bladder. World J Urol 25: 297-302, 2007. PMID: 17440731, DOI: 10.1007/s00345-007-0166-7.

68 Shin K, Lee J, Guo N, Kim J, Lim A, Qu L, Mysorekar IU and Beachy PA: Hedgehog/WNT feedback supports regenerative proliferation of epithelial stem cells in bladder. Nature 472: 110114, 2011. PMID: 21389986, DOI: 10.1038/nature09851.

69 Su G, Zhao Y, Wei J, Han J, Chen L, Xiao Z, Chen B and Dai $\mathrm{J}$ : The effect of forced growth of cells into 3D spheres using low attachment surfaces on the acquisition of stemness properties. Biomaterials 34: 3215-3222, 2013. PMID: 23439133, DOI: 10.1016/j.biomaterials.2013.01.044.
70 Huygens A, Crnolatac I, Develter J, Van Cleynenbreugel B, Van der Kwast $\mathrm{T}$ and de Witte PAM: Differential accumulation of hypericin in spheroids composed of T-24 transitional cell carcinoma cells expressing different levels of E-cadherin. J Urol 179: 2014-2019, 2008. PMID: 18355860, DOI: 10.1016/j.juro.2007.12.038.

71 Yang Y, Xu H, Shen J, Yang Y, Wu S, Xiao J, Xu Y, Liu X-Y and Chu L: RGD-modifided oncolytic adenovirus exhibited potent cytotoxic effect on CAR-negative bladder cancerinitiating cells. Cell Death Dis 6: e1760, 2015. PMID: 25973680, DOI: 10.1038/cddis.2015.128.
Received January 4, 2019

Revised January 31, 2019

Accepted February 4, 2019 